\title{
Muito além da transição epidemiológica: doenças crônicas no século XX
}

\author{
Far beyond the epidemiological transition: \\ chronic diseases in the twentieth century
}

\author{
Luiz Alves Araújo Neto \\ Doutorando, Programa de Pós-graduação em História das Ciências e da Saúde/Fiocruz. \\ orcid.org/0000-0001-7965-2957 \\ luizalvesan@hotmail.com
}

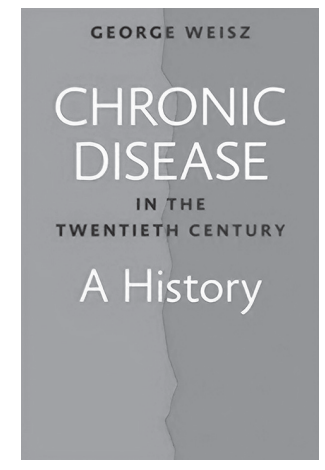

WEISZ, George. Chronic disease in the twentieth century: a history. Baltimore: Johns Hopkins University Press. 2014. $307 p$.
É recorrente entre pesquisadores, profissionais do campo da saúde e historiadores a noção de que a emergência das doenças crônicas como problemas de grande impacto epidemiológico é resultado direto de dois fenômenos de transição: demográfica e epidemiológica. O desenvolvimento médico-científico e o processo de modernização e urbanização promoveriam mudanças ecobiológicas e socioeconômicas diferentes em cada contexto nacional (Omran, 2005). Em Chronic disease in the twentieth century, George Weisz (2014) explora a questão sob outro olhar, direcionado à construção da própria categoria "doença crônica" como um objeto relevante para a medicina e a saúde pública.

Para tanto, utiliza uma vasta documentação de agências de regulação da saúde, medicina e bem-estar social, de periódicos médicos, de arquivos de hospitais e sociedades médicas, entre outros tipos de fontes impressas. Seu ponto central é demonstrar que a formulação do conceito de doença crônica não foi uma resposta à transição epidemiológica, e sim o contrário. De acordo com ele, é preciso compreender como é estabelecido um "conceito que inclui um câncer que pode matar dentro de meses, uma diabetes que requer gerenciamento longo, e a senilidade" (Weisz, 2014, p.1). ${ }^{1}$ Seu argumento é que a experiência dos EUA na formulação do conceito de doenças crônicas (principalmente na primeira metade do século XX) foi base para outros países e até mesmo agências internacionais (p.11).

Para elaborar seu argumento, Weisz utiliza três recursos metodológicos importantes. O primeiro consiste em dedicar considerável parte do livro (sete capítulos) à discussão sobre como o conceito de doenças crônicas foi construído nos EUA, mostrando as diversas negociações e mobilizações de atores e instituições para a afirmação de sua importância epidemiológica. O segundo é o exercício comparativo feito nos três últimos capítulos, abordando as experiências britânica e francesa e contrapondo-as ao caso norte-americano. Por último, o autor se detém majoritariamente nas discussões sobre as doenças crônicas 
como um grupo, sem aprofundar sua narrativa densa nas histórias específicas do câncer, das cardiopatias, da diabetes etc. Esses recursos permitiram uma análise centrada na mobilização de atores em torno de um conceito, mas sempre conectada aos demais processos históricos que cercam esses personagens.

Nos três primeiros capítulos, Weisz demonstra como a discussão em torno desse grupo de doenças emergiu nos EUA no entreguerras, abordando o tema por três ângulos. Primeiramente, os seguros saúde (health insurances) e a proposta de realização de exames periódicos como uma forma de prevenção de problemas que "degeneravam a raça". ${ }^{2}$ O segundo aspecto toca nas discussões sobre a ampliação do escopo da saúde pública, impulsionado pela criação dos primeiros programas de controle do câncer, notadamente o de Massachussets. Por último, apresenta o debate sobre o cuidado com os pacientes de doenças crônicas, com destaque para a controvérsia em torno do modelo de atenção (hospitais gerais, hospitais especializados ou home care).

Durante o governo Roosevelt, os atores envolvidos com o tema foram capazes de articular a realização do National Health Survey, um inquérito que mostraria com maior precisão o cenário epidemiológico norte-americano. O ponto central apontado por Weisz no quarto capítulo diz respeito à mudança epistemológica operada no inquérito, avaliando a morbidade (número de casos por população) em vez da mortalidade (número de mortes por população), o que deu maior evidência às doenças incapacitadoras (ou crônicas, para o período). A partir disso, atores e instituições mobilizaram-se para a criação de instituições de cuidado, estratégias de prevenção, e financiamento de pesquisas sobre as doenças crônicas, tendo como ponto de inflexão os relatórios da Comission of Chronic Illness (CCI). A atuação da CCI e a repercussão de seus dois principais relatórios (um sobre prevenção; o outro, sobre long-term care) são discutidas nos capítulos cinco, seis e sete.

Nos últimos capítulos, Weisz discute as especificidades do Reino Unido e da França na conformação do conceito de doenças crônicas. A principal diferença entre os três países é que, nos EUA, o conceito era associado ao cuidado de longa duração e a incapacitação do trabalhador, enquanto na França e na Inglaterra estava associado estritamente à velhice. Com isso, o tema teria levantado pouco interesse entre franceses e ingleses, visto que a preocupação maior residia nas doenças que atingiam a população em idade de trabalho (Weisz, 2014, p.172). Além disso, as diferentes organizações dos sistemas de saúde tiveram grande papel na forma como o tema foi discutido.

Um ponto merece destaque na comparação feita por Weisz. O autor argumenta repetidamente que o câncer configura um caso peculiar na sua análise, pois foi motor para a preocupação com as doenças crônicas, devido ao seu grande apelo social e às ações de controle da doença servirem de "modelo" para outros casos. Porém, as campanhas contra o câncer teriam fortalecido o foco em ações direcionadas a doenças específicas, enfraquecendo argumentos direcionados ao conjunto de doenças crônicas. Esse é o dilema principal enfrentado por Weisz: como estudar a história de um grupo de doenças em contextos em que predominam ações voltadas a problemas de saúde específicos?

Esse dilema fica mais claro ao estudar os casos europeus, em que as mobilizações para controle do câncer se iniciaram ainda no século XIX (Pinell, 2002; Moscucci, 2009), enquanto o debate sobre doenças crônicas ganhou força na segunda metade do XX. Um elemento que 
ajuda a elucidar a questão, pouco comentado no livro, mas explorado em artigo posterior (Weisz, Vignola-Gagné, 2015), é a atuação da OMS na construção de uma visão de doenças crônicas (não comunicáveis) que dialogasse com uma visão mais integral de saúde.

Finalmente, o livro demonstra bem como a emergência das doenças crônicas também foi um processo retórico, envolvendo negociações sobre conceitos e as formas de organização dos sistemas de saúde, indo além da interpretação clássica da transição epidemiológica.

\section{NOTAS}

${ }^{1}$ Nesta e nas demais citações de textos publicados em outros idiomas, a tradução é livre.

${ }^{2}$ Segundo Weisz, o conceito de doenças degenerativas estava relacionado, nos anos 1920 e 1930, à ideia de degeneração da nação. Médicos preocupados com a "vitalidade nacional" indicavam que hábitos associados à vida urbana, como o alcoolismo e o consumo de tabaco, bem como a maior presença de imigrantes no país, favoreciam a maior incidência de doenças que debilitavam a população, especialmente a classe trabalhadora. O agravo causado pelas doenças degenerativas, argumentava-se, tornaria os EUA uma "nação de inválidos". Ver Weisz (2014, p.22-23, 50, 75).

\section{REFERÊNCIAS}

MOSCUCCI, Ornella.

The British fight against cancer: publicity and education, 1900-1948. Social History of Medicine, v.23, n.2, p.356-373. 2009.

OMRAN, Abdel.

The epidemiologic transition: a theory of the epidemiology of population change. The Milbank Quarterly, v.83, n.4, p.731-757. 2005.

PINELL, Patrice.

The birth of a scourge: fight against cancer in France, 1890-1940. New York: Routledge. 2002.
WEISZ, George.

Chronic disease in the twentieth century: a history. Baltimore: Johns Hopkins University Press. 2014.

WEISZ, George; VIGNOLA-GAGNÉ, Etienne. The World Health Organization and the globalization of chronic noncommunicable disease. Population and Development Review, v.41, n.3, p.507-532. 2015. 